\title{
Thermal and Solution Stability of Lysozyme in the Presence of Sucrose, Glucose, and Trehalose
}

\author{
Susan James and Jennifer J. McManus* \\ Department of Chemistry, National University of Ireland Maynooth, Maynooth, Co. Kildare, Ireland
}

ABSTRACT: The effect of the sugars sucrose, glucose, and trehalose on the structural and colloidal stability of lysozyme has been investigated using differential scanning calorimetry and quasi-elastic light scattering, respectively. While sugars are known to increase the temperature at which thermal denaturation of protein occurs, it is not clear if, under the same solution conditions, greater colloidal stability is achieved. The measurements were carried out on lysozyme in three different buffer solutions, $0.05 \mathrm{M}$ sodium acetate ( $\mathrm{pH} 4.6), 0.05 \mathrm{M}$ sodium acetate with $5 \%(\mathrm{w} / \mathrm{v}) \mathrm{NaCl}$, and $10 \mathrm{mM}$ sodium phosphate ( $\mathrm{pH} 7.0)$. The results show that enhancement of structural stability in the presence of sugars is $\mathrm{pH}$, salt concentration, and sugar dependent. Enhancement of colloidal stability in the presence of sugars, while

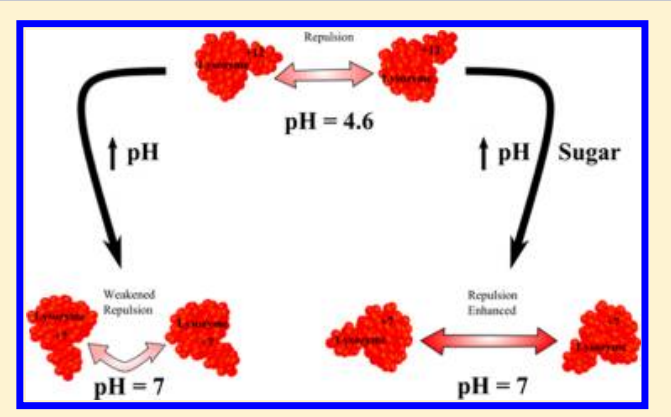
also $\mathrm{pH}$ and salt concentration dependent, as expected, only correlates with increases in the structural stability when the solution behavior is not dominated by highly stabilizing electrostatic repulsive interactions.

\section{INTRODUCTION}

Sugars are widely used excipients in the formulation of biotherapeutic products. ${ }^{1-7}$ Therapeutic proteins are produced and used for the treatment of various human diseases ${ }^{8}$ such as insulin for the treatment of diabetes, ${ }^{9}$ monoclonal antibodies for rheumatoid arthritis, ${ }^{10}$ interferon- $\alpha$ for leukemia, ${ }^{11}$ and interferon- $\beta$ for multiple sclerosis. ${ }^{12}$ Sugars are generally used as protein structure stabilizers, ${ }^{2,13}$ since additional stability is conferred to a protein during lyophilization by the addition of the sugar. ${ }^{14}$ Two hypotheses have been proposed to describe the stabilizing effect of sugars on proteins during lyophilization; one such hypothesis states that sugar acts as a water substituent and stabilizes proteins by forming hydrogen bonds at specific sites on the surface of the protein. ${ }^{1-16}$ Another hypothesis, referred to as the "vitrification hypothesis", states that disaccharides form sugar glasses, thereby immobilizing the protein molecules and providing protection against destabilizing reactions. ${ }^{15,16}$

Lysozyme is a globular protein with a molecular weight of approximately $14.7 \mathrm{kDa}$. Lysozyme has been used as a model protein for this study, since its biophysical properties are well understood and the specific contribution of the sugar to its stability over a range of solution conditions can easily be compared with that of the native protein. Lysozyme is a widely studied protein due to its rich phase behavior ${ }^{17,18}$ including crystallization, ${ }^{19}$ liquid-liquid phase separation, ${ }^{20-22}$ and the formation of equilibrium clusters ${ }^{23-25}$ and gels. ${ }^{24}$ The solution behavior of lysozyme is also well understood in terms of its interaction with salt ions. ${ }^{26-28}$

Protein stability by itself is a generic term, and it can be thought of in several ways. The stabilization of protein structure against thermal denaturation is referred to as its thermal or structural stability. Spectrophotometric techniques ${ }^{13,29-31}$ and differential scanning calorimetry (DSC) $)^{32,33}$ have been used to measure the effect of several additives on the thermal stability of proteins including sugars, ${ }^{13,29,30,32}$ amino acids, ${ }^{33}$ and salts. $^{31,32}$ These techniques have been used to measure the thermal transition temperature $\left(T_{\mathrm{m}}\right)$ and calorimetric enthalpy $(\Delta H)$ of protein solutions in the absence and presence of additives. Enhanced thermal stabilization is marked by an increase in $T_{\mathrm{m}}$ values. Thermal stabilization of proteins is important in industries where thermostable enzymes are produced with advantages of longer enzyme shelf life and lowered risk of microbial contamination. ${ }^{34}$

Here we define the solution stability of a protein as its ability to resist aggregation in solution by self-association, essentially its colloidal stability. Static light scattering, ${ }^{6,35}$ self-interaction chromatography, ${ }^{6}$ and quasi-elastic light scattering (QELS) ${ }^{35}$ have been used over several decades to monitor protein solution stability. The behavior of a protein in solution is controlled by a number of factors including $\mathrm{pH}^{33,36}$ salt type $^{26-28}$ salt concentration, ${ }^{35}$ amino acid sequence of the protein, ${ }^{37}$ and presence of excipients. ${ }^{6}$ At $\mathrm{pH}$ values away from the isoelectric point of the protein, there is an increase in charged groups which results in increased electrostatic repulsion. At $\mathrm{pH}$ values close to the isoelectric point, protein-protein interactions can be highly attractive, leading to protein aggregation, by self-association. ${ }^{8}$ The solution stability of a protein is also influenced by the salt concentration. The salt ions interact strongly with the water molecules surrounding the protein, thereby screening the long-range electrostatic repulsion and enhancing attractive van der Waals and hydrophobic effects. ${ }^{38}$ Salt ions are classified into kosmotropes (referred to as water structure makers) and

Received: April 23, 2012

Revised: July 30, 2012

Published: August 22, 2012 
chaotropes (referred to as water structure breakers). Recent research evaluated the effect of salt ions on protein interactions and aggregation. ${ }^{26}$ Rubin et al. observed ion-specific effects on protein interactions and aggregation which agrees well with the Hofmeister series and also found a strong correlation between the two. ${ }^{26}$

We make a clear distinction between the thermal and solution stability in this paper. While the thermal stability of the protein is related to the structural stability, the interaction of particles in solution is characterized by the net-interaction potential between those particles. This is often referred to as the self-interaction potential. The osmotic second virial coefficient, measured by static light scattering or self-interaction chromatography, is a thermodynamic parameter that characterizes protein interparticle interactions in solution under varying conditions. ${ }^{6}$ The collective diffusion coefficient $\left(D_{c}\right)$ of protein particles in solution for a range of concentrations is experimentally obtained from QELS. The zero concentration diffusion coefficient $\left(D_{0}\right)$ is obtained by extrapolating the $D_{c}$ data to zero concentration. The net protein interaction parameter $\left(k_{\mathrm{D}}\right)$ is measured as the slope of $D_{\mathrm{c}} / D_{0}$ versus protein concentration. The forces responsible for balancing the net protein interactions of particles include long-range repulsive electrostatic interactions, short-range attractive van der Waals interactions, attractive hydrophobic interactions, hydrogen bonding, and repulsive hydration effects. ${ }^{39}$ Positive $k_{\mathrm{D}}$ values represent stabilizing repulsive interactions, while negative $k_{\mathrm{D}}$ values represent attractive interactions.

A thorough insight into the colloidal and structural stability of proteins produced industrially, where proteins are produced in large quantities and stored for varying lengths of time as both liquid formulations and as lyophilized powders, is required to effectively understand the overall stability of the formulation. In this study, DSC and QELS have been used to assess both types of stability in solutions prepared under exactly the same conditions. While several researchers have investigated the effects of sugars on both structure ${ }^{2,13}$ and solution stability, ${ }^{6}$ this has not been done at the same time and under the same conditions before now. Therefore, this study allows us to directly compare the stabilities, at the same ionic strength and $\mathrm{pH}$ and establish if there is a correlation between the two. Our aim was to assess if increases in the structural stability of proteins due to the presence of sugars also resulted in an increase in the solution stability. If the mechanism for structural stabilization of the protein is by preferential exclusion, then this should add a repulsive component to the interaction potential, which should be experimentally observable. Our results show that, in the presence of sugars, the increase in thermal transition temperature (structural stability) does correspond to stabilizing repulsive interactions in solution (colloidal stability) only when the solution is not dominated by stabilizing electrostatic repulsive interactions.

\section{EXPERIMENTAL METHODS}

Chicken egg white lysozyme was purchased from Fisher Scientific or Calbiochem and was used without further purification. Lysozyme stock solutions with concentrations ranging up to $100 \mathrm{mg} / \mathrm{mL}$ were prepared by dissolving lysozyme in the following buffer solutions, $0.05 \mathrm{M}$ sodium acetate ( $\mathrm{pH} 4.6), 0.05 \mathrm{M}$ sodium acetate with $5 \%(\mathrm{w} / \mathrm{v}) \mathrm{NaCl}$ ( $\mathrm{pH} 4.6)$, and $10 \mathrm{mM}$ sodium phosphate ( $\mathrm{pH} 7.0)$. All reagents used were analytical grade. All buffers were prepared in Milli-Q water. The $\mathrm{pH}$ of lysozyme dissolved in all three buffer solutions was measured directly in the protein solution to ensure that the correct $\mathrm{pH}$ had been reached. Stock solutions were filtered through $0.22 \mu \mathrm{m}$ Millex-Gv Millipore (Millipore, Cork, Ireland) syringe driven filter units. Lysozyme concentrations were determined spectrophotometrically by $\mathrm{UV} / \mathrm{vis}$ absorbance using the extinction coefficient value for lysozyme of $2.64 \mathrm{~mL} \cdot \mathrm{mg}^{-1} \cdot \mathrm{cm}^{-1} \cdot{ }^{40}$ The volume fraction was calculated using $\phi=\nu c_{\mathrm{p}}$, where $\nu=0.703 \mathrm{~mL} / \mathrm{g}$ is the specific volume of lysozyme and $c_{\mathrm{p}}$ is the concentration in $\mathrm{mg} / \mathrm{mL}{ }^{40}$

AnalaR NORMAPUR D (+)-Saccharose, D-glucose, and trehalose dihydrate were purchased from VWR, Fisher Scientific, and Calbiochem, respectively, and used without further purification. Stock solutions of $40 \%(\mathrm{v} / \mathrm{v})$ of each sugar were prepared in the buffer in which the experiment was to be conducted and filtered through $0.22 \mu \mathrm{m}$ Millex-Gv Millipore (Millipore, Cork, Ireland) syringe driven filter units.

Lysozyme stock solutions were diluted to the required concentration using buffer, filtered through $0.02 \mu \mathrm{m}$ Anotop filter units (Whatman $\mathrm{GmbH}$, Dassel, Germany) and directly introduced into $5 \mathrm{~mm}$ cylindrical glass tubes (Hilgenberg $\mathrm{GmbH}$, Germany) for QELS experiments. For DSC measurements, $55 \mu \mathrm{L}$ of the filtered lysozyme sample solutions was loaded into stainless steel pans (Perkin-Elmer, Ireland), sealed, and analyzed. For experiments carried out in the presence of excipients, in addition to making up lysozyme solutions of the required concentration, the $40 \%(\mathrm{v} / \mathrm{v})$ sugar stock solutions were diluted to give a final concentration of $20 \%(\mathrm{v} / \mathrm{v})$. After preparation of the appropriate lysozyme/sugar solution, the samples were mixed, filtered through $0.02 \mu \mathrm{m}$ Anotop filter units (Whatman $\mathrm{GmbH}$, Dassel, Germany), and analyzed using QELS and DSC systems.

The quasi-elastic light scattering (QELS) system consisted of a compact ALV/CGS-3 Goniometer which is a self-contained system with a HeNe laser light source operating at a wavelength of $632.8 \mathrm{~nm}$ with an output power of $22 \mathrm{~mW}$, special optical fiber based detector, and ALV/LSE-5004 Light Scattering Electronics and Multiple Tau Digital Correlator. The timedependent fluctuations in the intensity of scattered light that occur are analyzed using the digital correlator which determined the autocorrelation function of the signal. The sample temperature was maintained by an external water bath circulator (Thermo Scientific DC30-K20) and was measured by a Pt-100 temperature probe immersed in a toluene index matching vat in which the sample was placed. All measurements were taken at a scattering angle of $90^{\circ}$, at a constant temperature of $293 \mathrm{~K}$. Each sample was measured for $1 \mathrm{~h}$. At the end of each DLS experiment, the protein concentrations were determined spectrophotometrically.

DSC measurements were conducted using the Perkin-Elmer Pyris-6 Differential Scanning Calorimeter (Perkin-Elmer, Ireland). Prior to the protein sample analysis, the Pyris-6 DSC was calibrated using indium. The temperature was increased from 298 to $373 \mathrm{~K}$ at a scan rate of $1 \mathrm{~K} / \mathrm{min}$. All data analysis including baseline subtractions from the thermograms for the DSC experiments was performed using the Origin version 6.1 software.

\section{RESULTS AND DISCUSSION}

Structural Stability of Lysozyme in the Presence of Sugars. The structural stability of a protein is a measure of the extent to which the structure of a protein is protected upon thermal denaturation and was probed using DSC. DSC has been employed to assess protein structural stability by several 
researchers. ${ }^{32,33}$ The thermal denaturation of a protein occurs at the thermal transition temperature $\left(T_{\mathrm{m}}\right)$ which is calculated as the midpoint of the thermogram peak, and integration of the area under the peak gives the calorimetric enthalpy $(\Delta H)$.

Figure 1 shows the melting of lysozyme under several buffer conditions. A considerable drop in the $T_{\mathrm{m}}$ value has been

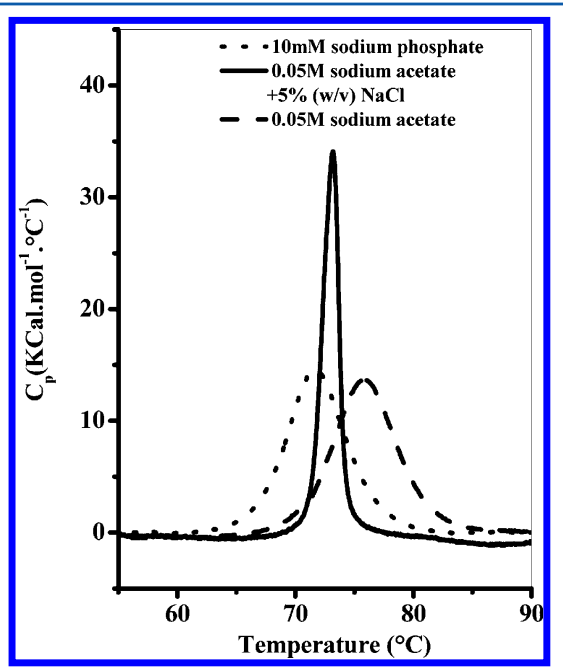

Figure 1. DSC thermogram of lysozyme in varying solution conditions.

observed for lysozyme in $0.05 \mathrm{M}$ sodium acetate with $5 \%(\mathrm{w} / \mathrm{v})$ $\mathrm{NaCl}(\mathrm{pH} 4.6)$ compared to $0.05 \mathrm{M}$ sodium acetate $(\mathrm{pH} 4.6)$ and is attributed to the presence of $\mathrm{NaCl}$ inducing a destabilizing effect on the unfolded state of the native protein by strengthening the attractive hydrophobic interactions between nonpolar residues ${ }^{33}$ as well as by perturbing the structure of water molecule around the protein. At this $\mathrm{pH}$ and ionic strength, there is also a decrease in the temperature range over which unfolding occurs. This may well be due to simultaneous unfolding and aggregation of the protein. Interestingly, this is a $\mathrm{pH}$ and ionic strength where lysozyme is also expected to be least colloidally stable. The lowest $T_{\mathrm{m}}$ value is reported for lysozyme in $10 \mathrm{mM}$ sodium phosphate $(\mathrm{pH} 7.0)$, and this clearly shows the destabilizing effect of higher $\mathrm{pH}$ on the structural stability of the protein due to enhanced attractive hydrophobic effects on the unfolded state of the protein at $\mathrm{pH}$ values close to the iso-electric point of lysozyme $(\mathrm{pI} \approx 11)$.

The enhancement in the structural stabilization of lysozyme under various solution conditions in the presence of sucrose, glucose, and trehalose has been presented in Figure 2 and the associated Table 1 . All of the sugars used for this study increase the structural stability of lysozyme, in all buffer conditions. The concentration of sugars selected for this study was expected to provide lysozyme its maximal structural stabilization while retaining its solubility in solution. ${ }^{30}$ The increase in thermal transition temperature $\left(\Delta T_{\mathrm{m}}\right)$ associated with the presence of sugars is an indication of the extent to which the structure of the protein is stabilized. The $\Delta T_{\mathrm{m}}$ value for lysozyme was in the range $5.7-8.3{ }^{\circ} \mathrm{C}$ depending on the solution condition and the type of sugar added. The $T_{\mathrm{m}}$ and $\Delta H$ values for lysozyme in $0.05 \mathrm{M}$ sodium acetate at $\mathrm{pH} 4.6$ with $5 \%(\mathrm{w} / \mathrm{v}) \mathrm{NaCl}$ are 73.2 ${ }^{\circ} \mathrm{C}$ and $61.3 \mathrm{kcal} \cdot \mathrm{mol}^{-1} \cdot{ }^{\circ} \mathrm{C}^{-1}$, respectively. This is consistent with the literature value of $73.7 \pm 0.6{ }^{\circ} \mathrm{C}$ and $59 \pm 5$ $\mathrm{kcal} \cdot \mathrm{mol}^{-1} \cdot{ }^{\circ} \mathrm{C}^{-1}$ measured for lysozyme in $4.85 \%(\mathrm{w} / \mathrm{v})$

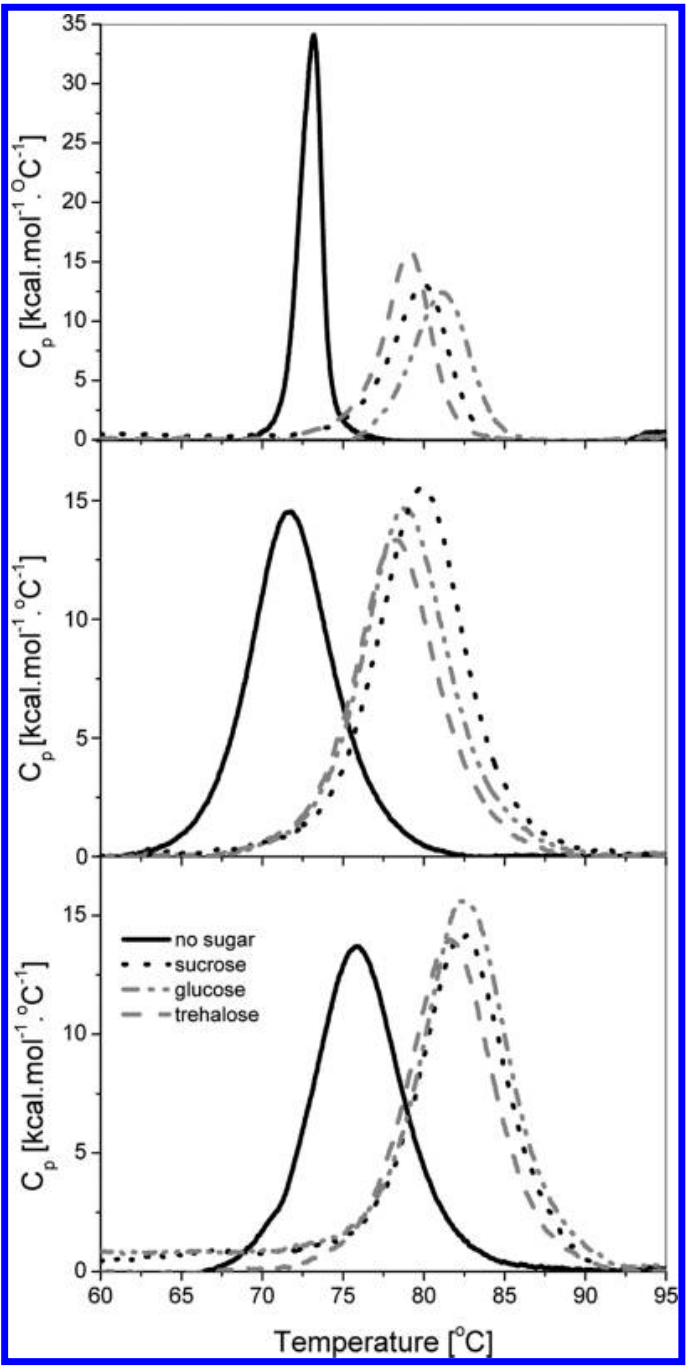

Figure 2. DSC thermogram of lysozyme in $0.05 \mathrm{M}$ sodium acetate at $\mathrm{pH} 4.6$ (bottom), $10 \mathrm{mM}$ sodium phosphate at $\mathrm{pH} 7.0$ (middle), and $0.05 \mathrm{M}$ sodium acetate with $5 \%(\mathrm{w} / \mathrm{v}) \mathrm{NaCl}$ (top) in the absence of sugar $(-)$ and in the presence of sucrose $(\cdots)$, glucose $(-. \cdot)$, and trehalose (---).

Table 1. Thermodynamic Parameters $\left(T_{\mathrm{m}}, \Delta H\right)$ for Lysozyme in Different Buffers at Different pH Values in the Absence and Presence of Sugars

$\begin{array}{lcc}\text { lysozyme buffer condition } & T_{\mathrm{m}}\left({ }^{\circ} \mathrm{C}\right) & \Delta H\left(\mathrm{kcal} \cdot \mathrm{mol}^{-1} \cdot{ }^{\circ} \mathrm{C}^{-1}\right) \\ & 0.05 \mathrm{M} \text { sodium acetate } \mathrm{pH} & \\ \text { no sugar } & 75.9 & 94.1 \\ \text { sucrose } & 82.4 & 98.2 \\ \text { glucose } & 82.3 & 112.2 \\ \text { trehalose } & 81.7 & 96.1 \\ & 10 \mathrm{mM} \text { sodium phosphate } \mathrm{pH} 7.0 & \\ \text { no sugar } & 71.7 & 95.6 \\ \text { sucrose } & 79.9 & 102.6 \\ \text { glucose } & 78.7 & 109.8 \\ \text { trehalose } & 78.3 & 90.5 \\ \text { 5\% }(\mathrm{w} / \mathrm{v}) \mathrm{NaCl} \text { in } 0.05 \mathrm{M} \text { sodium acetate } \mathrm{pH} & 4.6 \\ \text { no sugar } & 73.2 & 61.3 \\ \text { sucrose } & 79.9 & 59.3 \\ \text { glucose } & 81.1 & 54.4 \\ \text { trehalose } & 79.2 & 60.1\end{array}$


$\mathrm{NaCl}^{32}$ One hypothesis for the mechanism of structural stabilization of lysozyme in the presence of sugars is the concept of preferential hydration of protein. ${ }^{13,30}$ The preferential hydration mechanism proposes that sugars are excluded from the environment around the protein and are replaced by water. ${ }^{13,30,41}$ The preferential exclusion mechanism is supported by the increase in surface tension of water surrounding the protein due to the addition of sugars. $13,30,41$ However, the exact reason for the enhanced structural stabilization of proteins in the presence of sugars is still unclear. The $\Delta T_{\mathrm{m}}$ value or the degree of increase in the structural stability in the presence of all three sugars was found to be comparatively higher for lysozyme in $10 \mathrm{mM}$ sodium phosphate $(\mathrm{pH} 7.0)$ than for either of the $\mathrm{pH} 4.6$ buffers, and this is due to the greater stabilizing effect of sugars on the structure of lysozyme at $\mathrm{pH}$ values closer to the iso-electric point $(\mathrm{pI} \approx 11)$. While sucrose and trehalose remained stable in solution over extended time periods, glucose did not, as it is a reducing sugar and affects the structure of lysozyme by chemically reacting with its lysine and arginine residues via the Maillard reaction, ${ }^{38}$ but over the time scale of our experiment, it is expected to remain in its stable form and no "browning" of the solution was observed initially after a single heating cycle. Glucose was examined to understand the monosaccharide versus disaccharide effect rather than to assess glucose as a potential excipient.

Colloidal Stability of Lysozyme in the Presence of Sugars. Quasi-elastic light scattering may be used to determine the net protein interaction parameter $\left(k_{\mathrm{D}}\right)$. Both the sign and magnitude of $k_{\mathrm{D}}$ may be used to determine if net attractive or net repulsive interactions of the protein particle will dominate its behavior in solution. Proteins with positive $k_{\mathrm{D}}$ values interact via net repulsive interactions and are likely to be colloidally stable. Conversely, those with net attractive interactions have a tendency to aggregate in solution in a concentration dependent way.

Muschol and Rosenberger ${ }^{42}$ have deduced a relationship connecting the net protein interaction parameter $\left(k_{\mathrm{D}}\right)$ and $D_{\mathrm{c}} /$ $D_{0}$, as shown in eq 1 .

$$
D_{\mathrm{c}} / D_{0}=1+k_{\mathrm{D}} \phi
$$

where $\phi$ is the volume fraction of lysozyme. The parameter $k_{\mathrm{D}}$ is related to the second virial coefficient, $A_{2}$, by the following equation: ${ }^{43}$

$$
k_{\mathrm{D}}=2 A_{2} M-k_{\mathrm{f}}-2 \nu_{\mathrm{sp}}
$$

where $\nu_{\mathrm{sp}}$ is the partial specific volume of the molecule in question, and is unlikely to change in different buffer solutions, $M$ is the molecular weight of the protein, and $k_{\mathrm{f}}$ is related to the molecule's friction coefficient. $k_{\mathrm{D}}$ has been used to assess the net interaction potential for proteins by several researchers, ${ }^{21,44,45}$ and a strong correlation between $k_{\mathrm{D}}$ and $A_{2}$ has been demonstrated recently. ${ }^{44}$ While both $k_{\mathrm{D}}$ and $A_{2}$ are measured generally over the same concentration ranges, $k_{\mathrm{D}}$ may be measured at much lower volumes using microplate based QELS instrumentation and has the potential to be used in high throughput screening. While second virial coefficient values or equilibrium phase transitions are more widely used to measure interaction potentials, we believe that $k_{\mathrm{D}}$ is a convenient and reproducible way to assess colloidal stability. It is however more difficult to compare studies using $k_{\mathrm{D}}$ with other experimental or theoretical work, and there are hydrodynamic effects associated with $k_{\mathrm{D}}$ which are not yet well understood. ${ }^{46} k_{\mathrm{D}}$ values for lysozyme in a range of buffers at different pH's have been determined, and the extent to which the stability, as measured by $k_{\mathrm{D}}$, is altered in the presence of excipients such as sucrose, glucose, and trehalose has also been assessed.

Figure 3 shows QELS data for lysozyme in various buffer conditions over a range of protein concentrations. $k_{\mathrm{D}}$ values for

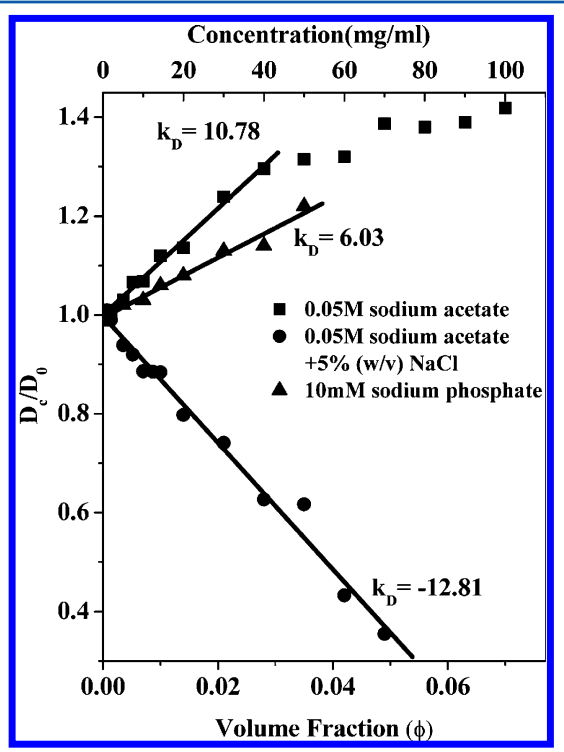

Figure 3. $D_{\mathrm{c}} / D_{0}$ as a function of volume fraction for lysozyme under various buffer conditions for experiments run at $T=20^{\circ} \mathrm{C}$.

lysozyme in various buffer conditions are also shown in Figure 3. Lysozyme in $0.05 \mathrm{M}$ sodium acetate at $\mathrm{pH} 4.6$ has a highly positive $k_{\mathrm{D}}$ value, indicating strong stabilizing repulsive electrostatic interactions and hence greater colloidal stability when compared to lysozyme in $10 \mathrm{mM}$ sodium phosphate at $\mathrm{pH} 7.0$ having a less positive $k_{\mathrm{D}}$ value, indicating less stabilizing repulsive interactions and hence weaker colloidal stability. The net surface charge of the lysozyme macroion is determined by the $\mathrm{pH}$ of the solution which contains it. At a $\mathrm{pH}$ of 4.6 , the lysozyme macro-ion carries $10-12$ positive charges. ${ }^{47}$ Thus, electrostatic Coulomb repulsion between the lysozyme macroions in the presence of counterions is the dominant interaction force which stabilizes the protein solution against aggregation. As the $\mathrm{pH}$ of the buffer solution which contains lysozyme approaches the isoelectric point $(\mathrm{pI} \approx 11),{ }^{47}$ the net surface charge of each lysozyme macro-ion decreases, which results in a decrease in the net electrostatic repulsive interactions.

Lysozyme in $0.05 \mathrm{M}$ sodium acetate at $\mathrm{pH} 4.6$ with $5 \%(\mathrm{w} / \mathrm{v})$ $\mathrm{NaCl}$ has negative $k_{\mathrm{D}}$ values indicating attractive interactions and weakened colloidal stability indicating that lysozyme is more prone to aggregation. This is also consistent with the decrease in the melt transition temperature observed in the DSC experiments. The addition of $5 \%(\mathrm{w} / \mathrm{v}) \mathrm{NaCl}$ at $\mathrm{pH} 4.6$ results in a sharp decrease in the $k_{\mathrm{D}}$ value for lysozyme from 10.78 (in the absence of salt) to -12.81 (with salt), indicating dominant attractive interactions. This is due to the screening or shielding effect introduced by salt, where long-range electrostatic repulsive forces between the positive charges of the lysozyme macroions are shielded, resulting in a decrease in the repulsive interactions and an enhancement of the attractive hydrophobic effects. ${ }^{6,37}$

The changes in the colloidal stability of lysozyme under various solution conditions in the presence of sucrose, glucose, 
and trehalose have been presented in Figures 4 and 5. As suggested previously, if sugars are preferentially excluded from

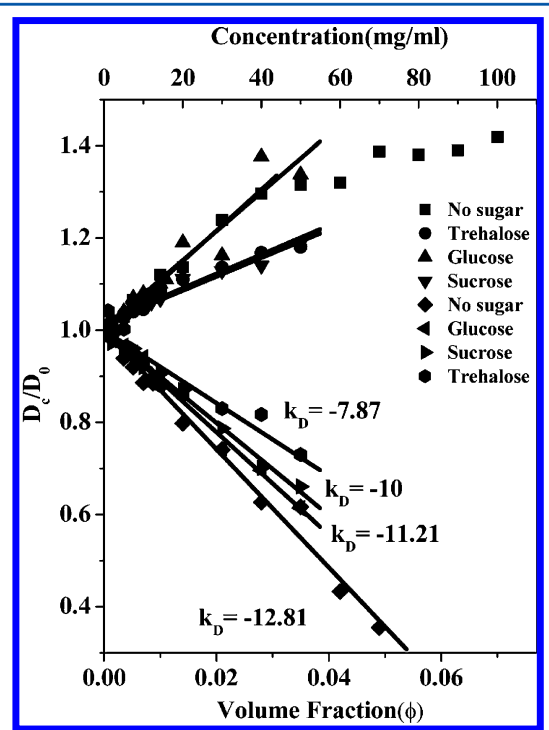

Figure 4. $D_{\mathrm{c}} / D_{0}$ as a function of volume fraction for lysozyme in 0.05 $\mathrm{M}$ sodium acetate at $\mathrm{pH} 4.6$ (top grouping; positive slope) and $0.05 \mathrm{M}$ sodium acetate with $5 \%(\mathrm{w} / \mathrm{v}) \mathrm{NaCl}$ at $\mathrm{pH} 4.6$ (bottom grouping; negative slope) in the absence and presence of sugars.

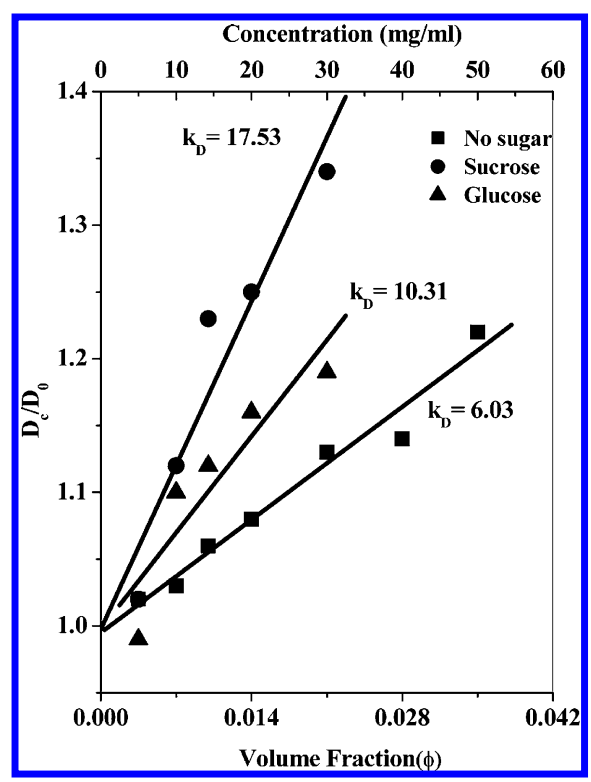

Figure 5. $D_{\mathrm{c}} / D_{0}$ as a function of volume fraction for lysozyme in 10 $\mathrm{mM}$ sodium phosphate at $\mathrm{pH} 7.0$ in the absence and presence of sugars.

the surface of the protein, thereby increasing hydration around the protein, this should lead to the introduction of an additional component to the repulsive part of the interaction potential, which should be measurable, if the effect is of sufficient magnitude to provide additional stabilization to the protein in solution. We have measured the impact of the addition of sugars to solutions of lysozyme, to assess if any change in the interaction potential is detected in the $k_{\mathrm{D}}$ value for the protein. We expected some enhancement in the colloidal stability of lysozyme in the presence of sugars under all three buffer conditions, but contrary to our expectations, there was no rise in the colloidal stability for lysozyme in $0.05 \mathrm{M}$ sodium acetate at $\mathrm{pH}$ 4.6, as shown in Figure 4, and this is explained on the basis of the surface charge and highly stabilizing repulsive electrostatic interactions at that specific $\mathrm{pH}$. As discussed earlier, lysozyme at $\mathrm{pH} 4.6$ has $10-12$ positive charges leading to highly stabilizing repulsive interactions so that any addition of excipient such as sugars does not induce an additional stabilizing effect on the protein, even if enhanced structural stability was attained under these conditions. An increase in colloidal stability for lysozyme in $0.05 \mathrm{M}$ sodium acetate at $\mathrm{pH}$ 4.6 with $5 \%(\mathrm{w} / \mathrm{v}$ ) $\mathrm{NaCl}$ (Figure 4) and $10 \mathrm{mM}$ sodium phosphate at $\mathrm{pH} 7.0$ (Figure 5) in the presence of sugars (glucose, sucrose, and trehalose) is observed. With the addition of both glucose and sucrose, the colloidal stability of lysozyme in $10 \mathrm{mM}$ sodium phosphate at $\mathrm{pH} 7.0$ is enhanced, as illustrated in Figure 6. This is consistent with the introduction

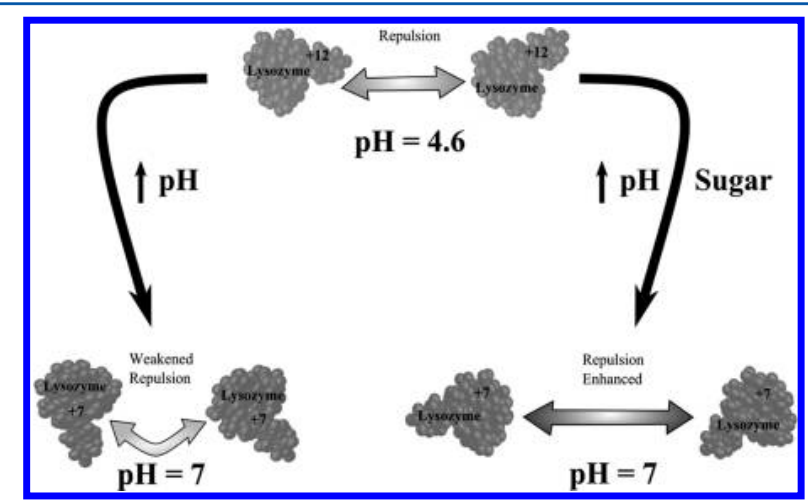

Figure 6. Illustration of the effect of sugars on the net interaction potential of lysozyme. Lysozyme has +12 charge at $\mathrm{pH} 4.6^{47}$ and +7 charge at $\mathrm{pH} 7.0 .^{50}$

of an additional component to the repulsive part of the interaction potential due to the presence of sugars which is reflected in the highly positive $k_{\mathrm{D}}$ values. While it is most likely that this is as a result of increased hydration around the protein, a decrease in the dielectric constant of the solution (and hence the van der Waals attraction) in the presence of sugars is also a possibility. This was proposed for the effect of increased colloidal stability on lysozyme in the presence of DMSO and glycerol $^{48}$ but was not found to be the case for Pseudomonas cepacia lipase in the presence of trehalose. ${ }^{49}$ At $\mathrm{pH} 4.6$ with $5 \%$ $(\mathrm{w} / \mathrm{v}) \mathrm{NaCl}$, the electrostatic charge is screened and the net interaction potential is attractive. The addition of sugar had little effect on the colloidal stability of lysozyme. Any additional repulsion due to the presence of the sugar is not enough to overcome the hydrophobic and van der Waals attractions. The overall increase in magnitude is sugar dependent, with sucrose having the greatest effect. Clearly, the presence of sugars under suitable solution conditions can alter the interaction potential but, in this case, only when electrostatic repulsion does not dominate the net interaction potential for the protein. This observation is in agreement with previous work. ${ }^{6}$ If tuned correctly, sugars may be used to stabilize the protein against aggregation in solution.

\section{CONCLUSION}

The main objective of this study was to analyze simultaneously the effects of sugars on the structural and colloidal stability of lysozyme and to assess if enhanced structural stability is directly correlated with an increase in the repulsive part of the net interaction potential, and hence the colloidal stability. Increased 
structural stability of lysozyme in the presence of the sugars glucose, sucrose, and trehalose was observed, indicated by an increase in $T_{\mathrm{m}}$ for the unfolding of the protein, with small differences arising from the specific type of sugar and solution conditions. The colloidal stability of lysozyme is altered in the presence of sugars only under specific solution conditions. A comparative study of the effect of sugars on the thermal and colloidal stability of lysozyme indicated that an increase in the structural stability of lysozyme in a specific solution condition due to the inclusion of sugars does not necessarily correspond to an increase in the colloidal stability of lysozyme under the same solution conditions. This is clearly illustrated in the case of lysozyme in $0.05 \mathrm{M}$ sodium acetate ( $\mathrm{pH} 4.6$ ). The addition of sugars had no effect on the net interaction potential between the proteins but did increase the thermal denaturation temperature. For lysozyme in $10 \mathrm{mM}$ sodium phosphate at $\mathrm{pH} 7.0$ and $0.05 \mathrm{M}$ sodium acetate with $5 \%(\mathrm{w} / \mathrm{v}) \mathrm{NaCl}$ at $\mathrm{pH}$ 4.6, the addition of sugars enhanced both structural and colloidal stability, with the largest effect observed at $\mathrm{pH}$ 7.0.

An in-depth knowledge of both the structural and colloidal stability is important for protein aggregation research. Many studies concentrate only on the structural stability of a protein (thermal stability) in order to understand if protein aggregation will occur. However, proteins aggregate by a variety of mechanisms, often through self-association. In this case, structural change is not required, and the net interaction potential is a more reliable way to predict aggregation potential (although exceptions are known ${ }^{36}$ ). As our experimental studies indicate, the appropriate choice of solution conditions and specific sugar may enhance protein stability for longer time periods by preventing aggregation through self-association from occurring. Among the sugars selected for our study, glucose has proved to provide stabilization. However, glucose is not utilized as an excipient for thermal stabilization of lysozyme, since it is a reducing sugar.

Clearly, this study is only a starting point. Lysozyme is a good model protein, which has been used here to establish a methodology to examine the various effects that excipients may have on the structural and colloidal stability of proteins. However, these effects may be protein specific, and these types of studies should be extended to include several types of proteins, including those produced industrially.

\section{AUTHOR INFORMATION}

\section{Corresponding Author}

*E-mail: jennifer.mcmanus@nuim.ie.

\section{Notes}

The authors declare no competing financial interest.

\section{ACKNOWLEDGMENTS}

We acknowledge financial support from Science Foundation Ireland Stokes Lectureship and NUI Maynooth. We thank Alice Blumlein for helpful discussions.

\section{REFERENCES}

(1) Liao, Y. H.; Brown, M. B.; Nazir, T.; Quader, A.; Martin, G. P. Pharm. Res. 2002, 19, 1847-1853.

(2) Lu, J.; Wang, X.; Liu, Y.; Ching, C. J. Therm. Anal. Calorim. 2007, 89, 913-919.

(3) Jovanovic, N.; Bouchard, A.; Sutter, M.; Speybroeck, M. V.; Hofland, G. W.; Witkamp, G.-J.; Crommelin, D. J. A.; Jiskoot, W. Int. J. Pharm. 2008, 346, 102-108.
(4) Lerbret, A.; Affouard, F.; Bordat, P.; Hédoux, A.; Guinet, Y.; Descamps, M. J. Chem. Phys. 2009, 131, 245103.

(5) Lins, R. D.; Pereira, C. S.; Hünenberger, P. H. Proteins: Struct., Funct., Bioinf. 2004, 55, 17-186.

(6) Valente, J. J.; Verma, K. S.; Manning, M. C.; Wilson, W. W.; Henry, C. S. Biophys. J. 2005, 89, 4211-4218.

(7) Patist, A.; Zoerb, H. Colloids Surf., B 2005, 40, 107-113.

(8) Chi, E. Y.; Krishnan, S.; Randolph, T. W.; Carpenter, J. F. Pharm. Res. 2003, 20, 1325-1336.

(9) Wang, M.-y.; Chen, L.; Clark, G. O.; Lee, Y.; Stevens, R. D.; Ilkayeva, O. R.; Wenner, B. R.; Bain, J. R.; Charron, M. J.; Newgard, C. B.; Unger, R. H. Proc. Natl. Acad. Sci. U.S.A. 2010, 107, 4813-4819.

(10) Smolen, J. S.; Aletaha, D.; Koeller, M.; Weisman, M. H.; Emery, P. Lancet 2007, 370, 1861-1874.

(11) Kiladjian, J.-J.; Mesa, R. A.; Hoffman, R. Blood 2011, 117, 4706-4715.

(12) Rodriguez, J.; Spearman, M.; Tharmalingam, T.; Sunley, K.; Lodewyks, C.; Huzel, N.; Butler, M. J. Biotechnol. 2010, 150, 509-518.

(13) Kaushik, J. K.; Bhat, R. J. Biol. Chem. 2003, 278, 26458-26465.

(14) Chang, L.; Shepherd, D.; Sun, J.; Ouellette, D.; Grant, K. L.; Tang, X.; Pikal, M. J. J. Pharm. Sci. 2005, 94, 1427-1444.

(15) Leslie, S. B.; Israeli, E.; Lighthart, B.; Crowe, J. H.; Crowe, L. M. Appl. Environ. Microbiol. 1995, 61, 3592-3597.

(16) Allison, S. D.; Chang, B.; Randolph, T. W.; Carpenter, J. F. Arch. Biochem. Biophys. 1999, 365, 289-298.

(17) Thakur, G.; Leblanc, R. M. Langmuir 2009, 25, 2842-2849.

(18) Magay, E.; Yoon, T.-S. J. Appl. Crystallogr. 2011, 44, 252-253.

(19) Neer, A. Methods 2004, 34, 266-272.

(20) Ishimoto, C.; Tanaka, T. Phys. Rev. Lett. 1977, 39, 474-477.

(21) Muschol, M.; Rosenberger, F. J. Chem. Phys. 1997, 107, 19531962.

(22) Jie, L.; Keith, C.; Rui-Jiang, L.; Xiu-Juan, W.; Chi-Bun, C. Biophys. Chem. 2004, 109, 105-112.

(23) Cardinaux, F.; Zaccarelli, E.; Stradner, A.; Bucciarelli, S.; Farago, B.; Egelhaaf, S. U.; Sciortino, F.; Schurtenberger, P. J. Phys. Chem. B 2011, 115, 7227-7237.

(24) Cardinaux, F.; Gibaud, T.; Stradner, A.; Schurtenberger, P. Phys. Rev. Lett. 2007, 99, 118301.

(25) Stradner, A.; Sedgwick, H.; Cardinaux, F.; Poon, W. C. K.; Egelhaaf, S. U.; Schurtenberger, P. Nature 2004, 432, 492-495.

(26) Rubin, J.; Miguel, A. S.; Bommarius, A. S.; Behrens, S. H. J. Phys. Chem. B 2010, 114, 4383-4387.

(27) Broering, J. M.; Bommarius, A. S. J. Phys. Chem. B 2005, 109, 20612-20619.

(28) Broering, J. M.; Bommarius, A. S. J. Phys. Chem. B 2008, 112, $12768-12775$.

(29) Kim, Y. S.; Jones, L. S.; Dong, A.; Kendrick, B. S.; Chang, B. S.; Manning, M. C.; Randolph, T. W.; Carpenter, J. F. Protein Sci. 2003, 12, 1252-1261.

(30) Kaushik, J. K.; Bhat, R. J. Phys. Chem. B 1998, 102, 7058-7066.

(31) Le Brun, V.; Friess, W.; Bassarab, S.; Garidel, P. Pharm. Dev. Technol. 2010, 15, 421-430.

(32) Singh, S.; Singh, J. AAPS PharmSciTech 2003, 4, 101-109.

(33) Santoro, M. M.; Liu, Y.; Khan, S. M. A.; Hou, L. X.; Bolen, D. W. Biochemistry 1992, 31, 5278-5283.

(34) Querol, E.; Perez-Pons, J. A.; Mozo-Villarias, A. Protein Eng. 1996, 9, 265-271.

(35) Curtis, R. A.; Prausnitz, J. M.; Blanch, H. W. Biotechnol. Bioeng. 1998, 57, 11-21.

(36) McManus, J. J.; Lomakin, A.; Ogun, O.; Pande, A.; Basan, M.; Pande, J.; Benedek, G. B. Proc. Natl. Acad. Sci. U.S.A. 2007, 104, 16856-16861.

(37) Anderson, J. L. Ind. Eng. Chem. Fundam. 1973, 12, 488-490.

(38) Lerbret, A.; Bordat, P.; Affouard, F.; Hédoux, A.; Guinet, Y.; Descamps, M. J. Phys. Chem. B 2007, 111, 9410-9420.

(39) Javid, N.; Vogtt, K.; Krywka, C.; Tolan, M.; Winter, R. ChemPhysChem 2007, 8, 679-689.

(40) Sophianopoulos, A. J.; Rhodes, C. K.; Holcomb, D. N.; Van Holde, K. E. J. Biol. Chem. 1962, 237, 1107-1112. 
(41) Lin, T.-Y.; Timasheff, S. N. Protein Sci. 1996, 5, 372-381.

(42) Muschol, M.; Rosenberger, F. J. Chem. Phys. 1995, 103, 1042410432.

(43) Gimel, J. C.; Brown, W. J. Chem. Phys. 1996, 104, 8112-8117.

(44) Lehermayr, C.; Mahler, H.-C.; Mäder, K; Fischer, S. J. Pharm. Sci. 2011, 100 (7), 2551-2561.

(45) Da Xing, S. L.; Li, J. J. Biol. Phys. 2004, 30, 313-324.

(46) Porcar, L.; Falus, P.; Chen, W.-R.; Faraone, A; Fratini, E.; Hong, K.; Baglioni, P.; Liu, U. J. Phys. Chem. Lett. 2010, 1, 126-129.

(47) Tanford, C.; Wagner, M. L. J. Am. Chem. Soc. 1954, 76, 33313336.

(48) Gögelein, C.; Wagner, D.; Cardinaux, F.; Nägele, G; Egelhaaf, S. J. Chem. Phys. 2012, 136, 015102-1-015102-12.

(49) Azizi, A.; Ranjbar, B.; Khajeh, K.; Ghodselahi, T.; Hoornam, S.; Mobasheri, H.; Ganjalikhany, M. R. Int. J. Biol. Macromol. 2011, 49, 652-656.

(50) Li, Y.; Kleijn, J. M.; Cohen Stuart, M. A.; Slaghek, T.; Timmermans, J.; Norde, W. Soft Matter 2011, 7, 1926-1935. 